DOI: $10.14451 / 2.126 .22$

\title{
ПОТРЕБИТЕЛЬСКОЕ КРЕДИТОВАНИЕ В РОССИИ: ГРАЖДАНСКО-ПРАВОВОЕ РЕГУЛИРОВАНИЕ И ЕГО ЭКОНОМИЧЕСКАЯ ХАРАКТЕРИСТИКА
}

\author{
(C) 2018 Архипова Евгения Михайловна \\ Начальник Финансового управления \\ $\mathrm{OOO}$ «Консалтинговая группа «Финиум» \\ 127055, г. Москва, ул. Новослободская, д. 14/19, стр. 8, пом. 2 \\ E-mail: earhortus@mail.ru
}

Проведен анализ российской гражданско-правовой регламентации потребительского кредитования, рассмотрена экономическая характеристика потребительского кредита. Представлена проблемная картина и перспективы развития гражданско-правового регулирования потребительского кредитования в России, показаны особенности сектора потребительского кредитования российского финансового рынка.

Ключевые слова: потребительский кредит, кредитор, заемщик, банк, потребительское кредитование, гражданско-правовое регулирование потребительского кредитования.

Потребительское кредитование является неотъемлемой катализирующей частью современной рыночной экономики, базирующейся на прогрессирующих формах финансового перераспределения. Потребительское кредитование заняло прочные позиции в экономической структуре социальной жизни населения, что служит предпосылкой уделения пристального внимания к экономическому и правовому анализу института розничного кредитования в России. Гражданско-правовая регламентация потребительского кредитования призвана придать розничному кредитованию цивилизованный статус, а договорам потребительского кредита безопасный контент для всех его участников.

Зародившись относительно недавно, потребительское кредитование упрочило свои позиции в общей структуре экономической активности населения. Объемы потребительского кредитования планомерно растут, что вызвано расширением сферы кредитования, ростом доступности розничного кредитования в силу снижения требований к платежеспособности заемщика (табл. 1).

Причинами стремительного роста удельного веса потребительского кредитования в общей структуре кредитной массы российского финансового рынка являются [15]: экономическая и политическая стабилизация, увеличение благосостояния населения, повышение финансовой грамотности населения (понимания потребителем банковских услуг катализирующего эффекта потребительского кредита).

Процесс развития потребительского кредитования в России сопровождается ростом объема просроченной задолженности при одновременном увеличении доступности кредита. Такое одноплановое экстенсивное и интенсивное развитие потребительского кредитования требует от юридической науки предложения все новых правовых механизмов защиты сторон договора от правовых, а значит и экономических рисков.

Необходимо отметить, что до недавнего времени как в действующем российском законодательстве, так и в мировой правовой доктрине отсутствовало четкое определение понятия «потребительский кредит» как юридической категории. Экономическая сущность потребительского кредита и рыночность процесса кредитования в целом возлагает на юридическую

Таблица 1. Темпы прироста показателей розничной кредитной активности банковского сектора (\% за год)

\begin{tabular}{|c|c|c|c|c|c|c|c|c|}
\hline & 2010 & 2011 & 2012 & 2013 & 2014 & 2015 & 2016 & 2017 \\
\hline $\begin{array}{l}\text { Кредиты и прочие средства, } \\
\text { предоставленные физическим } \\
\text { лицам }\end{array}$ & 14,3 & 35,9 & 39,4 & 28,7 & 13,8 & $-5,7$ & 1,1 & 12,7 \\
\hline \multicolumn{9}{|l|}{ Справочно: } \\
\hline Валовый внутренний продукт & 19,3 & 30,2 & 13,1 & 7,3 & 8,3 & 5,3 & 3,3 & 6,8 \\
\hline
\end{tabular}

Источник. Официальный сайт ЦБ РФ [8]. 
науку надежды в части обеспечения справедливого стороннего наблюдения, надзора и регулирования такого стихийного рыночного явления как потребительский кредит путем правотворчества и ревизии правовых норм, регулирующих отношения розничного кредитования.

Гражданско-правовую регулятивную базу потребительского кредитования в России составляют: Конституция РФ, Гражданский кодекс РФ, федеральные законы РФ, акты Центрального банка РФ, указы и постановления президента РФ, нормативно правовые акты министерств и ведомств, международные акты РФ и других государств, обычаи делового оборота.

Особое место в системе гражданско-правовой регламентации потребительского кредитования занимает ФЗ «О потребительском кредите (займе)» от 21.12.2013 г. № 353-Ф3 [2]. До принятия вышеуказанного закона, отношения участников потребительского кредитования рассматривались с позиций общего гражданского законодательства, не отвечая на все новые вопросы правовой регламентации таких специфических и социально значимых отношений как потребительское кредитование. Гражданско-правовое регулирование потребительского кредитования базировалось на общих положениях § 2 «Кредит» главы 42 «Заем и кредит» Гражданского кодекса РФ (часть вторая) от 26.01.1996 г. № 14-Ф3 [1], Федерального закона «О банках и банковской деятельности», Закона о защите прав потребителей, нормах, регламентирующих оплату товара, проданного в кредит, а также оплату товара в рассрочку. Сущность же понятий «потребительский кредит» и «договор потребительского кредитования» не были определены как самостоятельные юридические и экономические категории, не фиксировалась спецификация отношений потребительского кредитования вышеуказанными актами, что приводило к неопределенным с точки зрения правовых последствий результатам.

Ф3 «О потребительском кредите (займе)» от 21.12.2013 г. № 353-Ф3 обеспечил приведение уровня защиты заемщика потребительского кредита в соответствие с международными стандартами. Наиболее значимые изменения составили: установление легального определения потребительского кредита (займа); определение мер по защите прав и законных интересов заемщиков и кредиторов, введение ответственности за их нарушение; фиксация требований к струк- туре и содержанию договора (введены общие и индивидуальные условия договора; обозначена обязательность использования четкого, хорошо читающегося шрифта текста кредитного договора); нормативное введение понятия «полная стоимость кредита» (обязательность отображения полной стоимости кредита на первой странице в рамке крупным шрифтом, закрепление максимального размера полной стоимости для каждой категории кредитов); введение классификации категорий кредита (в зависимости от суммы, срока, наличия и вида обеспечения, цели кредита, использования при кредитовании электронного средства платежа и т.д.); определение срока принятия окончательного решения при заключении договора; установление возможности досрочного возврата кредита без штрафов; определение возможности самостоятельного выбора страховщика; ограничение деятельности коллекторов в способах воздействия на должников; установление мер государственного контроля и надзора при потребительском кредитовании.

Ф3 «О потребительском кредите (займе)» от 21.12.2013 г. № 353-Ф3 ликвидировал правовой пробел в сфере кредитования физических лиц (потребителей), чем обосновал переход на новый этап развития кредитных отношений между физическими лицами и кредитными организации, а следовательно способствовал оживлению деловой активности как локально в банковском секторе, так и в макроэкономическом масштабе.

Ревизия системы нормативно-правовых актов, прямо или косвенно регулирующих весь спектр отношений, связанных с потребительским кредитованием обозначила реперные точки правовой его корректировки и перспективы развития гражданского законодательства в части кредитования потребителей. Так правовые поправки были внесены в Федеральный закон «О банках и банковской деятельности», ФЗ «О кредитных историях», ФЗ «О несостоятельности (банкротстве)», ФЗ «О защите прав потребителей».

Федеральный закон «О банках и банковской деятельности» от 02.12.1990 г. № 395-1 [3] в ст. 30 зафиксировал отношения между Центральным банком, кредитными организациями, бюро кредитных историй и их клиентами в части защиты интересов заемщиков от незаконных финансовых операций.

Ф3 «О кредитных историях» от 30.12.2004 г. 
№ 218-Ф3 [4], сформулировал положения защищающие права и интересы кредитных институтов от недобросовестных заемщиков путем общего снижения кредитных рисков и повышения эффективности работы кредитных организаций.

Ф3 «О несостоятельности (банкротстве)» от 26.10.2002 г. № 127-Ф3 [5], в части новой главы 10 «Банкротство гражданина», ввел понятие «банкротства гражданина», определил условия и процедуру признания физического лица банкротом. Что позволило гражданам России на законных основаниях получить действенный механизм реструктуризации кредитных обязательств.

Ф3 «О защите прав потребителей» от 07.02.1992 № 2300-1 [6] обязал доводить до сведения потребителей информацию о фирменном наименовании организации; месте ее нахождении (адресе); режиме работы; о номере и сроке действия лицензии, органе ее выдавшем, лицензируемом виде деятельности; о цене; об условиях приобретения кредита; о полной сумме, подлежащей выплате; о графике погашения суммы, подлежащей выплате. Согласно федеральному законодательству данная информация должна быть доведена до сведения потребителей в наглядной и доступной форме до подписания потребителем кредитного договора.

Принятый 03 июля 2016 года Федеральный закон № 230-Ф3 «О защите прав и законных интересов физических лиц при осуществлении деятельности по возврату просроченной задолженности и о внесении изменений в Федеральный закон «О микрофинансовой деятельности и микрофинансовых организациях» [7] определил допустимые способы осуществления мер по взысканию просроченной задолженности, четко определив процедурные аспекты взыскания просроченной задолженности.

Сфера финансовых услуг является рискованной по своей природе в силу специфики торгуемого товара-услуги, включающего денежное обязательство в различных формах и видах [12]. Такая непосредственная связь товара-кредита с денежным эквивалентом влечет за собой обоюдную возможность неисполнения договорного обязательства в силу объективных (конъюнктура рынка, политические риски, форс-мажорные обстоятельства) или субъективных факторов (банковская кредитная политика, платежеспособность заемщика, недобросовестное поведение субъектов потребительского кредитования) в условиях динамичного развития рынка потребительского кредитования (табл. 2, 3).

Банк, осуществляющий розничное кредитование, на протяжении всего периода обслуживания кредитного портфеля потребительских кредитов находится в условиях частичной или полной неопределенности относительно платежеспособности заемщика [14], что влечет за собой стремление представителей юридических подразделений банков осуществлять локальный правовой протекционизм в части договорных отношений с заемщиком. Банк стремится обезопасить себя и включить в договор условия, которые позволят защитить банк от невозврата кредита. Однако не все условия кредитных договоров являются правомерными. Судебная

Таблица 2. Динамика кредитной активности, включая просроченную задолженность (в \% к активам)

\begin{tabular}{|l|c|c|c|c|c|}
\hline & 01.01 .17 & 01.01 .18 & 01.07 .18 & 01.10 .18 & 01.11 .18 \\
\hline $\begin{array}{l}\text { Кредиты и прочие средства, предоставленные } \\
\text { физическим лицам }\end{array}$ & 13.5 & 14,3 & 15,4 & 15,9 & 15,9 \\
Из них: просроченная задолженность & 1.1 & 1,0 & 0,9 & 0,9 & 0,9 \\
\hline
\end{tabular}

Источник. Официальный сайт ЦБ РФ [8]

Таблица 3. Основные характеристики кредитных операций банковского сектора (млрд.руб.)

\begin{tabular}{|l|c|c|c|c|c|}
\hline & \multicolumn{5}{|c|}{ Всего (в рублях и иностранной валюте) } \\
\cline { 2 - 6 } & 01.01 .17 & 01.01 .18 & 01.07 .18 & 01.10 .18 & 01.11 .18 \\
\hline Кредиты и прочие средства, предоставляемые & & & & \\
физическим лицам-резидентам & 10784,7 & 12151,9 & 13272,0 & 14147,2 & 14388,9 \\
Из них: просроченная задолженность & 856,3 & 846,8 & 811,8 & 812,8 & 810,1 \\
\hline Кредиты и прочие средства, предоставляемые & & & & & \\
физическим лицам-нерезидентам & 19,2 & 21,8 & 24,3 & 26,2 & 27,0 \\
Из них: просроченная задолженность & 1,6 & 2,0 & 2,5 & 2,6 & 2,6 \\
\hline
\end{tabular}

Источник. Официальный сайт ЦБ РФ [8] 
практика ответственности кредитора потребительского кредитования показывает, что наиболее частыми предметами оспаривания являются [9,10]: правомерность тарификации при выдаче и погашении кредита; допустимость принудительной продажи заемщику дополнительных услуг; наличие права банка на одностороннее изменение договора; границы правового поля осуществления коллекторской деятельности; обоснованность требования банком досрочного возврата кредита при нарушении платежной дисциплины; допустимость требованя оплаты процентов по кредиту в удвоенном размере, в случае просрочки возврата части кредита; возможность установления новых заемных процентов на уже просроченные заемные проценты (сложный процент); правомерность требования о досрочном исполнении обязательства по возврату средств в случае ухудшения финансового положения заемщика; возможность выдачи физическим лицам кредитов с так называемой плавающей процентной ставкой; включение в кредитный договор условия от том, что споры по иску банка и заемщика-гражданина рассматриваются судом по месту нахождения банка; включение в кредитный договор с заемщиком-гражданином условия о страховании его жизни и здоровья; фиксирование в кредитном договоре условия о запрете досрочного возврата кредита в течение определенного периода времени; допустимость взимания банком комиссии за досрочный возврат кредита.

Сфера финансовых услуг, оказываемых банками, в настоящее время характеризуется, с одной стороны, экстенсивным его развитием (наращивание объема розничного кредитного портфеля), а с другой все увеличивающейся интенсивной дефектностью наращиваемой кредитной массы розничного бизнеса банка. Судебная практика ответственности заемщика потребительского кредитования показывает, что наиболее частыми объектами оспаривания являются [11]: исполнение кредитных обязательств; определение подсудности споров, связанных с взысканием банками задолженности по кредитным договорам; оспаривание условий кредитных договоров; требования о расторжении кредитного договора; требования о взыскании задолженности по кредитному договору и обращении взыскания на заложенное имущество; осуществление взыскания задолженности по банковской (кредитной) карте; требование взыскания задолженности по основному долгу, процентов за пользование кредитом, неустойки за просрочку возврата займа; применение процедуры взыскания задолженности по кредитам в пользу третьих лиц; требование взыскания задолженности по кредитному договору и процентов за пользование кредитом в солидарном порядке.

Коллизии в урегулировании, неоднозначное толкование правовых норм приводят к нарушениям прав заемщиков, которые являются наиболее «слабой» стороной в кредитных правоотношениях. Договора потребительского кредитования зачастую противоречат гражданско-правовому законодательству и ущемляют права потребителей (например, в части применения санкций или неустойки за досрочное погашения долга, взимания неустоек за несвоевременное погашение потребительского кредита в необоснованном размере). Вследствие недобросовестного использования банками заведомо сильной переговорной позиции происходит дестабилизация доходного перераспределения экономических ресурсов, подрывается процесс установления системы имущественных отношений, основанной на идеях добросовестности, взаимной честности и уважения участников гражданских правоотношений.

Первоочередными задачами упорядочения гражданско-правовой базы потребительского кредитования являются: создание единой нормативной базы для расчета кредитоспособности потенциального заемщика и определения кредитной процентной ставки по потребительскому кредиту; усовершенствование методики определения кредитоспособности заемщика; совершенствование механизмов контроля за кредитными организациями в части осуществления потребительского кредитования; необходимость совершенствования правового поля применения банками и иными кредитным организациям добросовестного рекламного информирования потенциальных заемщиков и транспарентной договорной политики.

В правотворческой деятельности сферы потребительского кредитования необходимо сместить акценты с экстенсивного нормотворчества на интенсивный путь формирования гражданско-правовой базы регламентации розничного кредитования. Особо следует подчеркнуть необходимость обозначения проблемы кодификации банковского законодательства и выделе- 
ния сектора кредитного законодательства для детального и четкого регулирования кредитных отношений. Качественное углубление гражданско-правового нормотворчества целесообразно провести и в сфере смежных отраслей.

Социальная значимость потребительского кредитования неминуемо ведет к нарастанию рознично-кредитных транзакций, что делает объективной необходимостью усиление законодательного базиса не только собственно потребительского кредитования, но и рынка финансовых услуг в целом.

В силу специфики экономической и юридической природы потребительского кредитования, процесс оптимизации гражданско-правового фундамента розничного кредитования требует вовлечения специалистов как юридической, так и экономической науки. Только такой симбиотический подход к регулированию потребительского кредитования способен обеспечить баланс интересов заемщиков, кредиторов и государства.

Корректировку и обновление нормативно-правовой базы потребительского кредитования следует осуществлять в актуальном режиме, своевременно отвечая на вызовы рыночных механизмов потребительского кредитования.

В целом следует провести системную тотальную работу по приведению законодательства в области гражданско-правового регулирования потребительского кредитования в тождественное состояние, исключая наличие противоречивости и несбалансированности норм федерального законодательства. Российский рынок потребительского кредитования остро нуждается в обновленной гражданско-правововой платформе регулирования розничного кредитования, соответствующей современному уровню права стран развитого правопорядка.

Базируясь на договорном характере сделки, потребительское кредитование занимает особое место в системе договорного права гражданско-правовой отрасли. Договор потребительского кредитования является одним из важнейших институтов гражданского права в силу особой значимости регулируемых им общественных отношений для заемщика, кредитора, а также государства и общества в целом.

Изучению правовых компонентов потребительского кредитования российского финансового рынка, его актуальным и проблемным аспектам, не было уделено должного внимания со стороны научного сообщества. Указанное обстоятельство, безусловно, отрицательно влияет на качество развития договорных отношений в сфере потребительского кредитования России, тем более на фоне быстрого роста объемов предоставления кредитов физическим лицам.

Юридическая наука обязана сочетать в себе консервативные фундаментальные принципы и новаторские подходы к регулированию сущностных рыночных процессов, более глубоко и точечно отражать потребности современной системы хозяйствования. Именно такого комплексного экономико-правового подхода к разрешению существующих проблем требует современное состояние гражданско- правового регулирования потребительского кредитования.

Именно роль потребительского кредита, как связующего звена в перераспределительной цепи денежных средств экономического субъекта (гражданина), явилась предпосылкой стремительного развития розничного кредитования в России [13]. Что повлекло за собой задачу пристального анализа правотворческой и правоприменительной деятельности в области потребительского кредитования, ревизии сложившихся нормативных установок и создания новых эффективных правовых механизмов урегулирования деятельности в сфере потребительского кредита.

Отсутствие гармонизации экономической и юридической теории и практики в части договорных отношений между заемщиком и кредитором отрицательно влияет на качественное развитие потребительского кредитования в России, усложняя априори рыночную рискованную природу кредита недоработками и коллизиями правового характера.

Развитая рыночная экономика нормативно опирается на сбалансированную цивилизованную систему правовых институтов. Запаздывание и несогласованность процесса гражданско-правовой институционализации является основной причиной проблемной картины современного гражданско-правового регулирования потребительского кредитования.

Демократизация всех хозяйственных процессов развития общества ставит перед юридической наукой новые задачи активного поиска правовых механизмов достижения консенсуса между новыми экономическим реалиями и фундаментальными правовыми принципами.

Таким образом, перспективы граждан- 
ско-правового регулирования потребительского кредитования базируются на принципах комплексной экономико-правовой регламентации. Выработка единообразной эластичной гражданско-правовой платформы потребительского кредитования является необходимой предпосылкой сбалансированного развития не столько локально сектора потребительского кредитования, сколько макроэкономической стабилизации российской экономики в целом.

\section{Библиографический список}

1. Гражданский кодекс РФ (часть вторая) от 26.01.1996 г. № 14-ФЗ (ред. от 29.07.2018) (с изм. и доп., вступ. в силу 01.09.2018) [Электронный ресурс]// ИПС Консультантплюс. URL: http://www.consultant.ru/document/ cons_doc_LAW_294690/(дата обращения: 27.12.2018).

2. Федеральный закон «О потребительском кредите (займе)» от 21.12.2013 г. № 353-Ф3 (ред. от 07.03.2018) [Электронный ресурс]// ИПС Консультантплюс. URL: http://www.consultant.ru/document/cons_doc_ LAW_292705/ (дата обращения: 27.12.2018).

3. Федеральный закон «О банках и банковской деятельности» от 02.12.1990 г. № 395-1 (ред. от 28.11.2018) [Электронный ресурс]// ИПС Консультантплюс. URL: http://www.consultant.ru/document/cons_doc_ LAW_312181/ (дата обращения: 27.12.2018).

4. Федеральный закон «О кредитных историях» от 30.12.2004 г. № 218-ФЗ (ред. от 03.08.2018) [Электронный ресурс]// ИПС Консультантплюс. URL: http://www.consultant.ru/document/cons_doc_LAW_304237/(дата обращения: 27.12.2018).

5. Федеральный закон «О несостоятельности (банкротстве)» от 26.10.2002 г. № 127-ФЗ (ред. от 25.12.2018) [Электронный ресурс]// ИПС Консультантплюс. URL: http://www.consultant.ru/document/cons_doc_ LAW_314429/ (дата обращения: 27.12.2018).

6. Федеральный закон «О защите прав потребителей» от 07.02.1992 № 2300-1- ФЗ (ред. от 04.06.2018) [Электронный ресурс]// ИПС Консультантплюс. URL: http://www.consultant.ru/document/cons_doc_LAW_299539/ (дата обращения: 27.12.2018).

7. Федеральный закон от 03.07.2016 № 230-Ф3 «О защите прав и законных интересов физических лиц при осуществлении деятельности по возврату просроченной задолженности и о внесении изменений в Федеральный закон «О микрофинансовой деятельности и микрофинансовых организациях» (ред. от 12.11.2018) [Электронный ресурс]// ИПС Консультантплюс. URL: http://www.consultant.ru/document/cons_ doc_LAW_310848/ (дата обращения: 27.12.2018).

8. Официальный сайт «Центральный банк Российской Федерации».- URL: https:/www.cbr.ru/Collection/ Collection/File/10406/obs_194.pdf (дата обращения: 27.12.2018).

9. Обобщение судебной практики Калининского районного суда Тверской области по рассмотрению гражданских дел о взыскании по договору займа, кредитным договорам за 2014 год//Обзор судебной практики Калининского районного суда Тверской области. [Электронный ресурс] опубликовано 12.02.2016, [сайт]. [2016]. URL: http://kalininsky.twr.sudrf.ru/modules.php?name=sud_community\&id=221(дата обращения: 27.12.2018).

10. Обзор судебной практики по гражданским делам, связанным с разрешением споров об исполнении кредитных обязательств (утв. Президиумом Верховного Суда Российской Федерации 22 мая 2013 г.) // Бюллетень Верховного Суда Российской Федерации. 2013. № 9.

11. Информационное письмо Президиума ВАС РФ от 13 сентября 2011 г. № 147 «Обзор судебной практики разрешения споров, связанных с применением положений Гражданского кодекса Российской Федерации о кредитном договоре» // Вестник ВАС РФ. 2015. № 11.

12. Клевцов B.B., Архипова Е.М. Развитие научных представлений о кредите и ипотечном кредитовании // Вестник Тверского государственного университета. Серия: Экономика и управление. 2015. № 1-1. С. $100-107$.

13. Клевцов В.В., Замлелый А.Ю. Мегарегулирование и развитие финансово-кредитной системы Российской Федерации: результаты, риски, тенденции // Экономические науки. 2017. № 157. С. 55-58.

14. Пермякова Е.А. Проблемы потребительского кредитования // Символ науки. 2016. № 6. С.251-252.

15. Селиванов Т.А. Тенденции и проблемы розничного банковского кредитования в современной России // Инновационная наука. 2016. № 2. С.92-97. 